\title{
DIREITO PRIVADO E JUSTIÇA: O ARGUMENTO DA DIVISÃO INSTITUCIONAL DO TRABALHO ${ }^{1}$
}

Leandro Martins Zatinelli (UFMG) ${ }^{2}$ leandrozanitelli@gmail.com

\begin{abstract}
Rawls propõe uma "divisão do trabalho" entre as instituições que compõem a estrutura básica da sociedade e as regras diretamente aplicáveis a indivíduos e associações (grosso modo, o direito privado). $\mathrm{O}$ artigo expõe e refuta o argumento de que é compatível com a concepção rawlsiana de justiça defender um ideal de justiça não distributivo (como um ideal de justiça corretivo) para o direito privado. Alega-se, em suma, que o direito privado é necessário para manter o que Rawls chama de "justiça de fundo", bem como que esse papel pode ser desempenhado sem abrir mão de uma relativa simplicidade normativa
\end{abstract}

Keywords: direito privado; Rawls; divisão institucional do trabalho; justiça distributiva; justiça corretiva.

\section{Introdução}

Este artigo apresenta e critica um argumento para que uma concepção de direito privado, baseada em um ideal de justiça corretiva, seja considerada compatível com a concepção rawlsiana de justiça política. De acordo com esse argumento (o argumento da "divisão institucional do trabalho"), é peculiar à concepção de justiça defendida por Rawls, a "justiça como equidade", insistir em que os resultados de transações individuais somente serão legítimos se

\footnotetext{
${ }^{1}$ Recebido: 20-03-2018/ Aceito: 08-07-2019/ Publicado on-line: 12/04/2020.

2 Leandro Martins Zatinelli é Professor Adjunto na Faculdade de Direito da Universidade Federal de Minas Gerais, Belo Horizonte, MG. Brasil.
} 
mantidas certas condições de equanimidade, o que Rawls designa como "justiça de fundo". Essas condições de equanimidade, contudo, não devem ser asseguradas pelas regras às quais as transações individuais se sujeitam (grosso modo, pelo direito privado), mas pelas instituições (como, por exemplo, os tributos sobre a renda e a herança) que compõem a estrutura básica da sociedade. Depreende-se daí uma divisão do trabalho entre, de um lado, as instituições que fazem parte da referida estrutura e são encarregadas de preservar a justiça de fundo, e, de outro, o direito privado. Por fim, como é à estrutura básica que se aplicam os princípios distributivos (os princípios das liberdades, da equitativa igualdade de oportunidades e da diferença) da justiça rawlsiana, conclui-se que cabe a outras instituições, mas não ao direito privado, atender a esses princípios.

Procura-se demonstrar a seguir que esse argumento falha, e que, portanto, se algum lugar tiver de ser encontrado nas hostes rawlsianas para um ideal de justiça não distributivo (como o de justiça corretiva) a ser aplicado ao direito privado, esse lugar será outro que não o da divisão institucional do trabalho nos moldes que Rawls a propõe. Em resumo, afirma-se que a divisão institucional do trabalho, para ter a implicação de esquivar o direito privado de qualquer demanda distributiva, dependeria da confirmação de dois pressupostos, um implícito nas passagens em que Rawls trata dessa divisão, outro explícito. O pressuposto implícito é o de que a justiça de fundo pode ser realizada independentemente do direito privado. Esse pressuposto é, contudo, incongruente com os princípios que dão conteúdo à justiça de fundo, para cuja realização o direito privado é necessário. O pressuposto explícito é o de que manter a 
justiça de fundo por meio do direito privado importaria complicar as regras aplicáveis a transações individuais mais do que o recomendável. Esse pressuposto, argumenta-se, é falso: ainda que o direito privado deva atender a um especial imperativo de simplicidade, isso não impede que ele seja posto a serviço de princípios de justiça distributiva como os defendidos por Rawls.

O artigo é organizado da seguinte maneira. A seção 1 contém brevíssimos esclarecimentos sobre o ideal de justiça - distributivo ou corretivo - pertinente ao direito privado. A seção 2 apresenta as considerações de Rawls sobre a importância da justiça de fundo e a divisão institucional do trabalho. Nessa seção também se explica por que, com base em tal divisão, pode-se depreender que é compatível com a concepção de justiça rawlsiana a sujeição do direito privado à justiça corretiva. A seção 3 refuta o argumento da divisão institucional do trabalho em ambos seus pressupostos (implícito e explícito).

\section{DiREITO PRIVADO: JUSTIÇA DISTRIBUTIVA OU JUSTIÇA CORRETIVA?}

Uma questão fundamental no que concerne à relação entre direito privado e justiça ${ }^{3}$ é a da espécie de justiça pertinente a essa área do direito. Por um lado, o direito privado lida com questões cuja importância para concepções de

\footnotetext{
${ }^{3} \mathrm{O}$ artigo nada presume sobre a questão de saber o quanto o direito privado deve se conformar a algum ideal ou princípio de justiça, qualquer que seja. O tema do artigo somente será relevante, é claro, à medida que questões de justiça sejam relevantes para o direito privado. Por outro lado, não é necessário presumir que a justiça dê, invariavelmente, a palavra final; outras considerações podem ser tão ou até mais relevantes.
} 
justiça distributiva (algumas delas, ao menos) é indubitável: quais direitos de propriedade são reconhecidos; quais contratos são juridicamente eficazes e o conteúdo dessa eficácia; quais vítimas de dano têm direito a reparação; que direitos e deveres há entre familiares, em vida e post mortem, quais são as possíveis formas jurídicas da empresa, etc. Nenhuma concepção minimamente ambiciosa de justiça ocupada com a distribuição de bens como a riqueza ou o bemestar, poderá se dizer, já de saída, indiferente ao modo como o direito privado lida com questões como essas. Por outro lado, parece haver uma espécie de justiça pertinente às relações de direito privado cujo objeto não é a distribuição de bens em mais amplo espectro, mas a interação das partes. Trata-se, em outras palavras, de um ideal de justiça que atenta para o que uma das partes fez à outra (por exemplo, para o dano que uma causou à outra), e não para a situação delas em relação à distribuição de certos bens. Esse ideal de justiça costuma ser designado, por inspiração aristotélica, como justiça corretiva. ${ }^{4}$

Embora o conteúdo das duas espécies de justiça seja controvertido e, portanto, não seja pacífico afirmar o que a justiça distributiva e a justiça corretiva requerem, por exemplo, acerca de um dano que $A$ causou a $B$, é plausível que as prescrições de uma e da outra sejam conflitantes. Afinal, a justiça corretiva se interessará tão somente pelas características da interação entre $\mathrm{A}$ e $\mathrm{B}$ (isto é, pelas circunstâncias nas quais o primeiro causou dano ao segun-

\footnotetext{
${ }^{4}$ Para uma apresentação recente sobre o estado-da-arte, ver Scheffler (2015). Para trabalhos mais antigos sobre a relação entre direito privado e justiça (não necessariamente em uma perspectiva rawlsiana), consultem-se, entre outros, Kordana e Tabachnick (2005; 2006); Ripstein (2004); Weinrib (1995); Kronman (1980).
} 
do), enquanto a justiça distributiva terá em vista a situação das partes quanto a certo bem ou bens a distribuir.

Há várias maneiras de contornar a tensão entre justiça distributiva e justiça corretiva. Uma delas consiste em admitir a aplicação concorrente de princípios das duas espécies de justiça mediante soluções de compromisso. Por exemplo, A terá de reparar o dano que causou a B (tal como manda, digamos, a justiça corretiva), mas a indenização será reduzida pelo fato de $B$ ser mais rico do que $A$ (o que atende, também por hipótese, à justiça distributiva, ainda que não o bastante para se dizer que a situação de A e B após o pagamento da indenização seja justa, distributivamente falando).

Outra solução é negar validade a uma das espécies de justiça. Talvez A tenha que reparar o dano de $\mathrm{B}$ porque a justiça corretiva assim o requer e porque não há outro princípio válido de justiça. Outra, por fim, é propugnar pela compatibilidade das duas espécies de justiça, o que permitiria concluir que a reparação do dano de $\mathrm{B}$ por $\mathrm{A}$ atende a um princípio de justiça (como o corretivo) sem, contudo, contrariar a outro.

No restante do artigo, trataremos de um argumento para pensar que a compatibilidade entre justiça distributiva e corretiva é respaldada pela teoria da justiça de Rawls. ${ }^{5} \mathrm{~A}$ concepção de justiça política defendida por Rawls, a "justiça como equidade", é, notoriamente, uma concepção de justiça distributiva. Pode-se pensar, no entanto, que o direito privado é alheio à justiça como equidade e apto a se su-

${ }^{5}$ Outros compatibilistas são Nozick (1974) e Dworkin (2000). 
jeitar, consequentemente, aos preceitos de um ideal de justiça corretiva. Tal conclusão é motivada, como se explicará a seguir, pelas considerações de Rawls acerca da justiça como equidade como "justiça de fundo", bem como de uma "divisão institucional do trabalho" que essa justiça de fundo implicaria. ${ }^{6}$

\section{RAWLS, A JUSTIÇA DE FUNDO E A DIVISÃO INSTITUCIONAL DO TRABALHO}

Para entender por que a teoria da justiça de Rawls parece tratar como compatíveis as justiças distributiva e corretiva, é útil começar com as considerações do filósofo acerca do papel que a sua teoria atribui à estrutura básica da sociedade. Essa estrutura é constituída por instituições sociais ou, como ele diz, "pelo modo como essas instituições distribuem direitos e deveres e determinam a divisão de vantagens da cooperação social.” (RAWLS, 1999, p. 6) A justiça como equidade é uma concepção de justiça política com princípios aplicáveis especialmente à estrutura básica. Esses princípios diferem dos princípios aplicáveis às ações individuais.

\footnotetext{
${ }^{6} \mathrm{Um}$ argumento pela compatibilidade entre justiça distributiva e justiça corretiva em Rawls, que não será considerado aqui, é o seguinte. Tendo em vista que entre os princípios aplicáveis a indivíduos estão o princípio da equidade (principle of fairness) e os deveres naturais, e que esses incluem, respectivamente, obrigações contraídas por meio de promessas (RAWLS 1999, p. 97) e o dever de não causar dano a outrem (RAWLS 1999, p. 98), é patente a importância da justiça corretiva para os deveres individuais. Mas se a justiça corretiva é importante para esses deveres, então o direito também não pode ser indiferente a essa forma de justiça, sob pena de se mostrar um empecilho ao desenvolvimento moral dos cidadãos. Para um exemplo de um argumento assim (embora sem se referir, em particular, à teoria da justiça de Rawls), ver Shiffrin (2007).

7 "For us the primary subject of justice is the basic structure of society, or more exactly, the way in which the major social institutions distribute fundamental rights and duties and determine the division of advantages from social cooperation."
} 
Rawls explica que o papel da estrutura básica - o fato de essa estrutura se sujeitar a princípios especiais - diferencia a justiça como equidade tanto do utilitarismo quanto do libertarismo. O utilitarismo é entendido por Rawls como uma "teoria geral", cujo princípio último (a maximização da utilidade) se aplica às mais diferentes instâncias (RAWLS, 1996, p. 260-261). O princípio utilitarista para as instituições que compõem a estrutura básica é o mesmo, portanto, que regula a atividade de indivíduos e associações.

O libertarismo, por sua vez, não confere um papel especial à estrutura básica porque trata o Estado como uma associação entre outras, cujo poder sobre os cidadãos se sujeita à observância das mesmas regras aplicáveis às transações individuais (RAWLS, 1996, p. 264-265). O libertarismo é uma teoria sobre as condições para a aquisição originária de direitos e para a transferência voluntária desses direitos. Falta-lhe, assim, o conceito de "justiça de fundo", que são as condições para a equanimidade das transações individuais. Na justiça como equidade, é a estrutura básica que assegura essas condições (RAWLS, 1996, p. 266).

A respeito da justiça de fundo, Rawls faz duas afirmações importantes. Primeiro, a justiça de fundo não é assegurada de uma vez por todas. Ao contrário, partindo-se de uma situação inicial na qual as condições para a equanimidade dos resultados das transações individuais são atendidas, pode-se passar a uma outra situação na qual essas condições já não se verifiquem, ainda que só haja transações voluntárias e que todos os acordos sejam cumpridos (RAWLS, 1996, p. 266). É papel das instituições que compõem a estrutura básica interferir, então, para que a justiça 
de fundo seja restaurada. Segundo, não é factível submeter transações individuais a regras que evitem que a justiça de fundo seja solapada. Aqui Rawls chama a atenção para o fato de que os efeitos das transações individuais sobre a justiça de fundo muitas vezes não são diretos ou imediatos. A complicada engenharia social para evitar esses efeitos deletérios somente poderia ser realizada, assim, por meio de regras de difícil ou custosa aplicação. Trata-se, portanto, de um inconveniente prático. "As regras aplicáveis aos acordos", diz Rawls, "são, afinal, diretrizes públicas e práticas, e não funções matemáticas que possam ser tão complicadas quanto se possa imaginar." (RAWLS, 1996, p. 268)

$\mathrm{O}$ inconveniente de tentar preservar a justiça de fundo por meio das regras aplicáveis às transações individuais, leva Rawls a propor o que chama de "divisão institucional do trabalho". Essa divisão não é senão a divisão institucional de tarefas que decorre, de uma parte, do papel quanto à justiça de fundo que a justiça como equidade atribui à estrutura básica e, de outra, à indesejabilidade de esse papel ser exercido pelas regras aplicáveis às transações individuais:

Assim (...) chegamos à ideia de uma divisão do trabalho entre duas

\footnotetext{
8 "The rules applying to agreements are, after all, practical and public directives, and not mathematical functions which may be as complicated as one can imagine”. Logo em seguida (ibid.), ele acrescenta: "Portanto qualquer esquema sensível de regras evitará exceder a capacidade dos indivíduos para entendê-las e segui-las com suficiente facilidade, nem irá sobrecarregar os cidadãos com demandas de informação e previsão que eles não estão normalmente aptos a atender. Indivíduos e associações não conseguem compreender as ramificações de suas ações em conjunto, nem se pode esperar que antecipem o impacto de circunstâncias futuras sobre tendências atuais" ("thus any sensible scheme of rules will not exceed the capacity of individuals to grasp and follow them with sufficient ease, nor will it burden citizens with requirements of knowledge and foresight that they cannot normally meet. Individuals and associations cannot comprehend the ramifications of their particular actions viewed collectively, nor can they be expected to foresee future circumstances that shape and transform present tendencies").
} 
espécies de regras sociais e as diferentes instituições por meio das quais essas regras são realizadas. A estrutura básica compreende em primeiro lugar as instituições que definem a base social e que incluem também as operações que continuamente fazem ajustes e compensam as inevitáveis tendências contrárias à equidade de fundo, tais como impostos sobre a renda e heranças destinados a igualar a propriedade. Essa estrutura também faz valer por meio do sistema jurídico um outro conjunto de regras que governam transações e acordos entre indivíduos e associações (o direito contratual, e assim por diante). Regras sobre dolo, coação e outras do gênero pertencem a esse conjunto e satisfazem a requerimentos de simplicidade e praticidade. Elas são desenhadas para deixar que indivíduos e associações ajam efetivamente em busca de seus fins e sem restrições excessivas.

Para concluir: começamos com a estrutura básica e tentamos verificar como essa estrutura mesma faz os ajustes necessários para preservar a justiça de fundo. $\mathrm{O}$ que procuramos, com efeito, é uma divisão institucional do trabalho entre a estrutura básica e as regras que se aplicam diretamente a indivíduos e associações, e que devem ser seguidas por eles em transações particulares. Se essa divisão puder ser estabelecida, indivíduos e associações ficarão livres para promover seus fins mais efetivamente à sombra da estrutura básica, seguros em saber que em outro lugar do sistema social as correções necessárias para preservar a justiça de fundo estão sendo feitas (RAWLS, 1996, p. 268-269). ${ }^{9}$

\footnotetext{
9 "Thus (...) we arrive at the idea of a division of labor between two kinds of social rules, and the different institutional forms in which these rules are realized. The basic structure comprises first the institutions that define the social background and includes as well those operations that continually adjust and compensate for the inevitable tendencies away from background fairness, for example, such operations as income and inheritance taxation designed to even out the ownership of property. This structure also enforces through the legal system another set of rules that govern the transactions and agreements between individuals and associations (the law of contract, and so on). The rules relating to fraud and duress, and the like, belong to these rules, and satisfy the requirements of simplicity and practicality. They are framed to leave individuals and associations free to act effectively in pursuit of their ends and without excessive constraints. To conclude: we start with the basic structure and try to see how this structure itself should make the adjustments necessary to preserve background justice. What we look for, in effect, is an institutional division of labor between the basic structure and the rules applying directly to individuals and associations and to be followed by them in particular transactions. If this division can be established, individuals and associations are then left free to advance their ends more effectively within the framework of the basic structure, secure in the knowledge that elsewhere in the social system the Cont.
} 


\title{
Embora Rawls não o diga, não há nada que, à primeira
} vista, impeça que as regras aplicáveis às transações individuais se conformem a um ideal de justiça corretiva: primeiro, porque essas regras não se sujeitam às demandas distributivas da justiça de fundo; segundo, porque a indiferença aos efeitos mediatos e indiretos das transações individuais permite que a justiça corretiva seja incorporada ao direito privado sem suscitar o inconveniente mencionado por Rawls ao tratar da justiça de fundo. ${ }^{10}$

\section{Divisão institucional do trabalho e direito privado}

\begin{abstract}
necessary corrections to preserve background justice are being made." Para considerações similares sobre a divisão institucional do trabalho, v. Rawls (2001, p. 53-54). É controvertido na literatura (KORDANA; TABACHNICK 2005, p. 605-606, n. 34) se, na frase "This structure also enforces", o termo "structure" se refere à estrutura básica, caso no qual a primeira parte do trecho transcrito acima incluiria na estrutura básica tanto as instituições incumbidas de manter a justiça de fundo (como a tributação da renda e da herança) quanto as regras aplicáveis às transações individuais. A questão, porém, é de somenos importância. Pertencentes ou não à estrutura básica, o fato é que Rawls nega às últimas regras qualquer papel quanto à justiça de fundo. Logo, não são as regras aplicáveis às transações individuais que vão assegurar as condições de equanimidade dessas transações e que estarão, portanto, encarregadas de realizar os princípios nos quais as referidas condições se baseiam.

${ }^{10}$ É importante diferenciar o argumento recém esboçado e um outro também favorável a acomodar a justiça corretiva a um ideal de justiça eminentemente distributivo como o rawlsiano. $\mathrm{O}$ argumento da divisão institucional do trabalho se refere, como visto, ao inconveniente prático de incluir o direito privado entre as instituições incumbidas de preservar a justiça de fundo. Esse argumento é diferente do que Rawls usa, por vezes, para justificar a estrutura básica como objeto da justiça como equidade, o qual apela para a impropriedade da aplicação do(s) mesmo(s) princípio(s) de justiça a objetos diversos. É a essa impropriedade que Rawls alude, por exemplo, ao negar que os princípios da sua concepção de justiça se apliquem a associações como igrejas e universidades (RAWLS, 1996, p. 261; 2001, p. 10, n. 8). Esse argumento do pluralismo, ou da diversidade e irredutibilidade dos princípios de justiça válidos para diferentes objetos ou instâncias, é um argumento patentemente distinto do exposto acima, o qual, ao invés de uma inadequação material, limita-se a alegar a impossibilidade para realizar institucionalmente (por meio de regras suficientemente simples) certas demandas da justiça. Scheffler (2006, p. 106-107) distingue os dois argumentos e propõe chamar o argumento do pluralismo de argumento da divisão do trabalho moral.
\end{abstract}


Esta seção trata do argumento da divisão institucional do trabalho como argumento para que o direito privado fique imune aos princípios de justiça distributiva da justiça como equidade, e livre, consequentemente, para se amoldar aos preceitos de um ideal de justiça não distributivo. Lembre-se, para começar, do papel especial que Rawls atribui à estrutura básica em relação às transações individuais. Esse papel, como visto acima, é o de assegurar a justiça de fundo, isto é, as condições para que transações voluntárias sejam equânimes.

A ideia de negar ao direito privado qualquer papel quanto à justiça de fundo tem dois pressupostos, um deles explícito no argumento de Rawls sobre a divisão institucional do trabalho, o outro implícito. O pressuposto explícito é o de que o direito privado é inapto a preservar a justiça de fundo, porque, para fazê-lo, seria preciso complicá-lo mais do que o desejável. O pressuposto implícito é o de que outras instituições são suficientes para resguardar a justiça de fundo." Do contrário, de nada valeria, do ponto de vista da justiça, que os contratos e outras ações reguladas pelo direito privado se submetam a regras simples e fáceis de aplicar, já que, para a concepção rawlsiana de justiça, os resultados

\footnotetext{
${ }^{11} \mathrm{Ou}$ nem tão implícito assim. Repare na parte final da passagem transcrita anteriormente (RAWLS, 1996, p. 269): "se essa divisão puder ser estabelecida, indivíduos e associações ficarão livres para promover seus fins mais efetivamente à sombra da estrutura básica, seguros em saber que em outro lugar do sistema social as correções necessárias para preservar a justiça de fundo estão sendo feitas." Em Justice as Fairness, contudo, Rawls (2001, p. 53) afirma que "princípios diretamente aplicáveis a acordos (por exemplo, o direito contratual) não são, sozinhos, suficientes para preservar a justiça de fundo" ("principles applying to these agreements directly (for example, the law of contract) do not alone suffice to preserve background justice"). Isso tanto pode ser entendido como referência a um caso hipotético no qual confiássemos apenas no direito privado para preservar a justiça de fundo (tarefa para a qual ele se mostraria, então, insuficiente) quanto como expressão da ideia de que o direito privado é necessário (mas não suficiente) à justiça de fundo. Essa segunda interpretação é contrariada, no entanto, pela proposta da divisão institucional do trabalho.
} 
de transações voluntárias serão legítimos se e somente se certas condições de equanimidade (isto é, a justiça de fundo) forem atendidas.

Comecemos com o pressuposto implícito. Embora Rawls não o diga ao apresentar a ideia da divisão institucional do trabalho, é de se entender que o conteúdo da justiça de fundo seja determinado pelos princípios da justiça como equidade. $\mathrm{O}$ primeiro princípio, ou princípio das liberdades, assegura aos cidadãos certas liberdades básicas. ${ }^{12} \mathrm{O}$ segundo princípio sujeita desigualdades sociais e econômicas a duas condições (RAWLS, 2001, p. 42-43): primeiro, essas desigualdades devem estar atreladas a cargos e posições para a ocupação dos quais todos gozem de equitativa igualdade de oportunidades; segundo, elas devem ser para a maior vantagem possível ("to the greatest benefit") dos cidadãos em pior situação, o que Rawls designa como princípio da diferença.

Tendo em vista sua especial importância para as considerações que seguem, convém tratar um pouco mais detalhadamente do princípio da diferença. Para entender o que esse princípio determina, imagine um arranjo institucional sob o qual as expectativas dos cidadãos quanto à distribuição de certos bens, como renda, sejam as mesmas (por exemplo, com instituições que eliminem diferenças de renda causadas pelo mercado). Se, em um cenário alternativo (isto é, sob instituições diversas), as expectativas dos cidadãos fo-

\footnotetext{
${ }^{12}$ Rawls (2001, p. 42): o primeiro princípio garante a cada um "um plenamente adequado esquema de iguais liberdades básicas, compatível com um comparável esquema de liberdades para todos os demais" ("a fully adequate scheme of equal basic liberties, which scheme is compatible with the same scheme of liberties for all").
} 
rem ainda melhores, ainda que desiguais (isto é, se, nesse cenário, as expectativas dos cidadãos, inclusive aqueles em pior situação, forem melhores do que sob um arranjo institucional estritamente igualitário, graças, por exemplo, ao efeito de incentivo de diferenças de renda), então o princípio da diferença pede que abandonemos a distribuição igual em favor de uma mais benéfica a todos. Esse princípio pede, ademais, que toleremos a desigualdade até o ponto em que os cidadãos em pior situação parem de se beneficiar - em outras palavras, que nos movamos em uma curva de desigualdade até o ponto em que as expectativas dos cidadãos em desvantagem sejam as melhores possíveis.

Voltando à divisão institucional do trabalho, repare-se que essa divisão só é plausível, portanto, se as instituições encarregadas de manter a justiça de fundo forem aptas a realizar os dois princípios recém mencionados. É pouco plausível que esse seja o caso, no entanto, se as instituições em questão não incluírem o direito privado. Aqui há dois pontos a considerar. Primeiro, não é difícil imaginar que o direito privado admita violações às liberdades básicas e à equitativa igualdade de oportunidades - por exemplo, com a tolerância à discriminação em contratos ou por meio de indenizações aplicadas a certos exercícios da liberdade de expressão. Ainda assim, poder-se-ia conceder que as restrições impostas por esses dois princípios ao conteúdo do direito privado são pontuais, isto é, que os princípios das liberdades e da equitativa igualdade de oportunidades sejam indiferentes à maioria das decisões em matéria de direi- 
to privado, ${ }^{13}$ como, por exemplo, a de sujeitar a formação de contratos à regra da expedição ou à da recepção. ${ }^{14}$ Segundo, o fato de o princípio da diferença admitir desigualdades apenas sob a condição de que a situação dos cidadãos menos aquinhoados seja maximizada, determina que todo o direito privado - ou, ao menos, todas as decisões sobre a matéria do direito privado com impacto sobre os cidadãos em desvantagem - seja tratado como parte da justiça de fundo. ${ }^{15}$ Em contraste com os demais princípios da justiça como equidade, portanto, o princípio da diferença não tem implicações meramente pontuais para o direito privado. Até mesmo uma questão de detalhe sobre o regime da formação dos contratos, como a escolha entre as regras da expedição e da recepção, pode se sujeitar ao princípio da diferença - contanto que o impacto das regras em questão sobre os cidadãos em pior situação não seja o mesmo. ${ }^{16}$

\footnotetext{
${ }^{13}$ Para uma opinião nesse sentido em relação ao direito contratual, ver Scheffler (2015, p. $224-$ 225).

${ }^{14}$ Sobre a formação de um contrato mediante a aceitação de uma proposta, pode-se estipular a regra de que o contrato se forma assim que a resposta é enviada (regra da expedição) ou somente com a chegada dessa resposta ao proponente (regra da recepção). O art. 434 do código civil brasileiro (BRASIL, 2002) adota, com ressalvas, a regra da expedição.

${ }^{15} \mathrm{Na}$ literatura, a sujeição do direito privado ao princípio da diferença é tratada por vezes como dependente da resposta à questão prévia de saber se o direito privado é ou não parte da estrutura básica da sociedade e se, portanto, faz ou não parte das instituições às quais os princípios da justiça como equidade, entre eles o da diferença, se aplicam. É falso supor, porém, que o conteúdo da estrutura básica possa ser definido por mera estipulação ao invés de pela adequação material. Fazem parte da estrutura básica as instituições relevantes para a justiça (no caso de Rawls, as instituições relevantes para a distribuição das vantagens e ônus da cooperação social) e às quais os princípios da justiça como equidade se afirmem como materialmente adequados. A adequação material de um princípio a uma instituição, por sua vez, pode ser refutada ou, no espírito da "virada política" de Rawls, simplesmente não afirmada, sob a alegação de que fazê-lo poria em xeque a aceitabilidade da justiça como equidade nas circunstâncias do que Rawls chama de pluralismo razoável. À falta, porém, de um argumento em algum desses sentidos, é descabido excluir da estrutura básica o direito privado ou quaisquer outras instituições.

${ }^{16}$ Scheffler discorda dessa interpretação que, para ele, contraria o pluralismo (ou a "divisão do trabalho moral") defendido por Rawls. Segundo Scheffler (2015, p. 227): "Se, em seus acordos e transações privados, os indivíduos devessem ser guiados por regras designadas tão somente para Cont.
} 
Sobre esse último ponto, pode-se objetar que, embora possivelmente distintas, as consequências da decisão sobre uma questão de detalhe como a da formação do contrato pela expedição ou recepção da resposta são difíceis de mensurar, de modo que, embora provável que o princípio da diferença não seja indiferente à escolha, não seja de esperar que um juiz ou legislador decida a questão motivado pelo princípio em questão, por lhe faltarem as informações para tanto. Essa objeção é importante, porque a viabilidade institucional é, sem dúvida, algo a considerar quando se trata da justiça como equidade. Rawls não está interessado em princípios de justiça per se, mas em princípios de justiça que as instituições sociais sejam capazes de realizar. Logo, se, devido à falta de informações, o princípio da diferença se mostrasse um critério insuficientemente confiável para a conformação do direito privado, essa seria uma razão para interpretar as condições de equanimidade que constituem a justiça de fundo como condições que podem ser atendidas independentemente do direito privado - ou, ao menos, que podem ser atendidas sem que toda e qualquer questão de

alcançar os objetivos distributivos do princípio da diferença, Rawls andaria na direção de uma teoria geral aplicável à conduta individual tanto quanto às instituições" ("if, in their private agreements and transactions, individuals are to be guided by rules designed solely to achieve the distributive aims of the difference principle, this pushes Rawls's view in the direction of a general theory that applies to individual conduct no less than to institutions"). Deve-se evitar, porém, a confusão entre sujeitar o direito privado ao princípio da diferença e sujeitar a esse mesmo princípio as ações individuais reguladas pelo direito privado. Uma coisa não implica a outra, nem mesmo, como Scheffler afirma logo após essa passagem, como um "igualitarismo de regras" (em contraposição a um "igualitarismo de atos") aplicado a indivíduos e associações. Tendo em vista a insistência de Rawls em contrastar a sua concepção de justiça e o utilitarismo, o argumento da pluralidade continua sendo um argumento poderoso contra a ideia de sujeitar a totalidade do direito privado à justiça distributiva. Para defender a opinião diametralmente oposta implicada pela divisão institucional do trabalho, no entanto, é preciso mais do que simplesmente aludir à recusa de Rawls a que os princípios da justiça como equidade sejam princípios materialmente adequados a indivíduos e associações. 
detalhe sobre o direito privado seja resolvida do modo mais favorável aos cidadãos em pior situação.

Mesmo que se admita, no entanto, que a aplicabilidade do princípio da diferença depende de uma certa previsibilidade quanto aos efeitos de decisões institucionais sobre os cidadãos menos favorecidos, não é o caso de depreender daí que a justiça de fundo prescinda do direito privado (ou de todo o conteúdo do direito privado indiferente aos princípios das liberdades e da equitativa igualdade de oportunidades). Considere-se, em primeiro lugar, que a previsibilidade necessária a que uma decisão institucional seja governada pelo princípio da diferença é alguma previsibilidade, não mais do que isso. Fora do direito privado, o impacto de medidas legislativas sobre os cidadãos em pior situação também costuma ser um tanto incerto, de modo que ou aceitamos que decisões governamentais sejam tomadas da maneira que, a partir das informações disponíveis, pareça ser a mais benéfica para esses cidadãos, ou então abrimos mão de aplicar o princípio da diferença de uma vez por todas. Em segundo lugar, embora talvez não seja mesmo possível prever, com alguma (suficiente) segurança, os efeitos sobre os cidadãos em pior situação, de uma mudança de detalhe na legislação do direito privado, é pouco plausível que o mesmo valha para decisões institucionais mais fundamentais, tal como, por exemplo, a de submeter os contratos a um regime de laissez-faire ou interventivo. ${ }^{17}$

\footnotetext{
${ }^{17}$ É claro que se pode divergir sobre a característica fundamental - liberal ou interventiva - de um direito contratual mais favorável possível aos cidadãos em pior situação, mas essa divergência não parece ser distinta da que estamos sujeitos a encontrar em outras áreas de reconhecida aplicação do princípio da diferença, como o direito tributário.
} 
Em conclusão, um problema com uma divisão institucional do trabalho pela qual o direito privado fique alheio à justiça distributiva é que, ao menos da maneira como Rawls a concebe, a justiça de fundo não pode ser realizada independentemente do direito privado. Para que os resultados das transações individuais sejam equânimes, é necessário que o direito privado seja conformado de maneira a não violar os princípios das liberdades e da equitativa igualdade de oportunidades. É também necessário que, ao menos em suas características fundamentais, esse direito se mostre o mais vantajoso possível para os cidadãos em pior situação.

Passemos agora ao pressuposto explícito do argumento, o de que se o direito privado for incluído entre as instituições encarregadas de manter a justiça de fundo, renunciaríamos à simplicidade desejável a um direito a ser seguido por indivíduos e associações em suas transações voluntárias. A esse respeito, pode-se, em primeiro lugar, ponderar se a simplicidade que Rawls tem em vista pode ser alcançada (mesmo por um direito privado indiferente à justiça de fundo) e se é, de fato, uma característica especialmente desejável do direito privado. Scheffler (2015, p. 219) lembra, quanto ao primeiro ponto, que o direito contratual não é tão simples a ponto de ser possível entendê-lo sem a ajuda de um advogado (a afirmação é presumivelmente feita acerca do direito norte-americano, mas vale para a generalidade dos países hoje em dia). Além disso, como também lembra Scheffler (2015, p. 219), o direito privado não é a única área do direito cujas regras se aplicam diretamente a transações entre particulares - parte do direito tributário, por exemplo, também é assim. Logo, é duvidoso que a simplicidade seja especialmente importante para o direito privado - 
mais importante do que para o direito em geral.

Essas objeções, apesar de importantes, não são decisivas. Mesmo que o direito privado não seja simples como Rawls dá a entender, a divisão institucional do trabalho pode se manter atraente como meio de evitar que o direito privado se complique ainda mais. Afinal, nos países em que atualmente as dúvidas sobre o seu conteúdo só são sanadas com a ajuda de advogados, o direito privado costuma resultar de um processo histórico muito mais atento à conveniência de indivíduos e associações do que provavelmente seria um legislador cujo único propósito fosse ajustar essa área do direito aos princípios da justiça como equidade. Além do mais, não é de esperar que, ao propor a divisão institucional do trabalho, Rawls, um filósofo, estivesse atento aos precisos limites de cada setor do direito, de maneira que, ao se referir às "regras que se aplicam diretamente a indivíduos e associações, e que devem ser seguidas por eles em transações particulares (RAWLS, 1996, p. 269), ${ }^{18}$ ele tivesse em mente a distinção entre direito público e privado tal como feita pelos juristas. Logo, se há regras do direito tributário que seja pertinente definir como "regras aplicáveis diretamente a indivíduos e associações" e que, como tais, devam ser especialmente simples, não haveria mal maior em dispensá-las, junto com o direito privado, da tarefa de preservar a justiça de fundo. ${ }^{19}$

A objeção decisiva à simplicidade como justificativa

\footnotetext{
18 "rules applying directly to individuals and associations and to be followed by them in particular transactions".

${ }^{19}$ Assim como faria pouca diferença, para a questão que nos interessa aqui, se disposições pontuais do direito privado forem incluídas na primeira parte da divisão, isto é, como instituições encarregadas de manter a justiça de fundo.
} 
para a divisão institucional do trabalho é que, de fato, não há nada que impeça o direito privado de ser conformado distributivamente e permanecer simples. Consideremos mais uma vez as demandas distributivas da justiça rawlsiana, dividindo a análise desta vez em três partes, uma para cada princípio (ou subprincípio).

Comecemos pelo princípio das liberdades. Sejam quais forem precisamente as suas implicações, não é crível que, para atender ao princípio em questão, o direito privado tenha de ser consideravelmente mais complexo do que ordinariamente é. Isso porque, primeiro, a garantia das liberdades não impõe que se tenham em vista os efeitos mediatos das instituições e, em consequência, que o conteúdo das regras jurídicas seja conformado em função desses efeitos. ${ }^{20}$ Segundo, as liberdades devem ser igualmente asseguradas a todos, independentemente da riqueza e de características como sexo e raça. Logo, eventuais disposições de direito privado feitas para satisfazer ao princípio das liberdades também podem ignorar diferenças relativas a essas e outras características.

Em relação ao princípio da equitativa igualdade de oportunidades, pode-se cogitar de dois modos de intervenção do direito privado. Um consiste em coibir atos que sejam tidos, em si mesmos e independentemente de seus efeitos mediatos ou somados aos de outros atos, como contrários à igualdade de oportunidades - por exemplo, a pro-

\footnotetext{
${ }^{20}$ Como ressalva, se os efeitos mediatos do direito privado e das demais instituições consistirem em uma larga concentração da riqueza, infringir-se-á o valor equitativo das liberdades políticas, uma parte do princípio das liberdades (RAWLS, 1999, p. 197-198). É bem possível, no entanto, que uma concentração da riqueza contrária ao referido valor equitativo possa ser evitada exclusivamente por outros meios que não o direito privado.
} 
ibição à venda de um imóvel para um negro ou a cláusula testamentária que estipule a perda do direito à herança para a filha que se case com um judeu. Outro modo de intervenção miraria atos cujos efeitos mediatos ou somados aos de outros atos sejam contrários à igualdade de oportunidades - por exemplo, o ato de fazer comércio com pessoa da mesma religião ou etnia. Rawls pode ter razão ao supor que medidas da segunda espécie são uma ameaça à simplicidade do direito privado, sobretudo se elas envolverem uma obrigação de contratar com certas pessoas. Por outro lado, beira o absurdo pensar que a divisão institucional do trabalho se oponha a medidas da primeira espécie, não só porque tais medidas podem ser implantadas por meio de regras um tanto simples (por exemplo, uma regra sobre a invalidade de cláusulas de restrição à venda para pessoas de determinada raça), como porque, contanto que estejamos falando de coibir práticas negociais reputadas em si mesmas como contrárias à igualdade de oportunidades, trata-se de algo que só o direito privado poderá fazer. A invalidade da cláusula de resolução do testamento para a filha que se case com um judeu é, por definição, uma medida de direito privado.

Passemos, por fim, ao princípio da diferença. É nesse terreno que o receio de pôr em risco a simplicidade do direito privado, ao encarregá-lo de manter a justiça de fundo, é mais infundado. É que o objetivo de maximizar a vantagem dos cidadãos em pior situação pode ser perseguido sob quaisquer limites que se queira impor em nome da simplicidade. Digamos que, para não atentar contra um imperativo de simplicidade, o legislador do direito privado tenha de se limitar a soluções que já tenham sido adotadas, seja no 
seu país, seja em outros. Se há duas ou mais regras alternativas conhecidas (e, portanto, aprovadas no teste da simplicidade) cujos efeitos sobre os cidadãos em pior situação sejam distintos, o legislador poderá fazer a escolha com base no princípio da diferença, promulgando a regra cujos efeitos sobre os cidadãos em pior situação sejam mais benéfi$\cos ^{21}$

\section{CONCLUSÃO}

O argumento da divisão institucional do trabalho para manter o direito privado a salvo das demandas de uma concepção distributiva de justiça, a exemplo da justiça como equidade, falha em seus dois pressupostos, um implícito no texto em que essa divisão do trabalho é proposta por Rawls, o outro explícito. O pressuposto implícito é o de que a justiça de fundo, no sentido que Rawls dá a essa expressão, pode ser resguardada sem a ajuda do direito privado. Esse pressuposto é falso, não só pelo potencial do direito privado para violar pontualmente os princípios das liberdades e da equitativa igualdade de oportunidades, mas, sobretudo, porque o direito privado é como um todo necessário à realização do princípio da diferença.

O pressuposto explícito é o de que não é possível fazer com que o direito privado atenda aos princípios da justiça como equidade sem abrir mão da simplicidade conveniente a um direito diretamente aplicável às transações entre particulares. Em relação, contudo, ao princípio das liberdades e

\footnotetext{
${ }^{21}$ O legislador também obedecerá ao princípio da diferença se os efeitos das regras em questão para os cidadãos em desvantagem se equivalerem, e qualquer das regras for escolhida.
} 
a uma parte do princípio da equitativa igualdade de oportunidades, o que se requer do direito privado parecem ser medidas um tanto singelas, capazes de serem implantadas por meio de regras de fácil aplicação. Por fim, não há incompatibilidade entre a aplicação do princípio da diferença e um imperativo de simplicidade, qualquer que seja ele, contanto que esse imperativo permita que o direito privado seja conformado de diferentes maneiras, e que essas conformações sejam comparáveis com base em seus efeitos sobre os cidadãos em pior situação.

\begin{abstract}
Rawls proposes a division of labor between the institutions composing society's basic structure and the rules applying directly to individuals and associations (private law, roughly speaking). The paper exposes and criticizes the claim that a non-distributive ideal of justice (such as an ideal of corrective justice) is suited for private law under Rawls' account. It is argued that private law is a necessary condition for preserving what Rawls calls "background justice", as well as that it can perform this role while maintaining a relative normative simplicity.
\end{abstract}

Keywords: private law; Rawls; institutional division of labor; distributive justice; corrective justice.

\title{
REFERENCES
}

BRASIL. Lei $\mathrm{n}^{\circ} 10.406$, de 10 de janeiro de 2002. Institui o Código Civil.

\section{DWORKIN, D. Sovereign Virtue: the Theory and Prac- tice of Equality. Cambridge: Harvard University Press, 2000}

KORDANA; K. A.; TABACKNICK, D. H. "Rawls and contract law". George Washington Law Review, v. 73, n. 3, 2005, p. 598-632. 
. "On belling the cat: Rawls and tort as corrective justice. Virginia Law Review, v. 92, n. 7, 2006, p. 12791310.

KRONMAN, A. T. "Contract law and distributive justice". Yale Law Journal, v. 89, n. 3, 1980, p. 472-511.

NOZICK, R. Anarchy, State, and Utopia. Oxford: Blackwell, 1974.

RAWLS, J. Political Liberalism. Nova York: Columbia University Press, 1996.

Press, 1999.

A Theory of Justice. 2 ed. Cambridge: Belknap

. Justice as Fairness: a Restatement. Cambridge: Belknap Press, 2001.

RIPSTEIN, A. "The division of responsibility and the law of tort. Fordham Law Review, v. 72, n. 5, 2004, p. 1811-1844.

SCHEFFLER, S. "Is the basic structure basic?" In SYPNOWICH, C. (org.). The Egalitarian Conscience: Essays in Honor of G. A. Cohen. Oxford University Press, 2006, p.102-129.

. "Distributive justice, the basic structure and the place of private law". Oxford Journal of Legal Studies, v. 35,2015, p. $213-235$.

"Distributive justice, the basic structure and the place of private law. Oxford Journal of Legal Studies, v. 35 , n. 2, 2015, p. 213-235. 
SHIFFRIN, S. V. "The divergence of contract and promise". Harvard Law Review, v. 120, 2007, p. 708-753.

WEINRIB, E. J. The Idea of Private Law. Cambridge: Harvard University Press, 1995. 